are markedly less caustic than hot concentrated sulphuric acid when dropped on the skin.

Massachosetrs Instetote of Technology,

November, 1902.

\title{
THE PREVENTION OF BUMPING.
}

BY HEYWARD SCUDDER.

Received November 28, 5902 .

A sINGLE glass capillary tube when used according to the following directions will stop most cases of bumping that occur in ordinary laboratory work. The method is simple, effective and introduces into the liquid no foreign substance except glass and one small bubble of air. In order to carry it out successfully the following details of procedure must be carefully observed.

The origin of the use of a capillary is obscure. The earliest published reference that I have found is by Gernez. ${ }^{1}$ Since these references are only incidental and therefore difficult to find, it is quite possible that there may be an earlier one. I have tried all the methods published (most of which are only for special cases), and have found none so simple or of such wide application as the one presented here.

The capillary is made by drawing out a piece of glass tubing until the internal diameter is about 0.5 to I millimeter. A seal is then made by holding the tube horizontally in the edge of the flame of a Bunsen burner, until the walls have melted together. The tube is bent, if necessary, or held horizontally till cold. For most purposes the seal should be about I $\mathrm{cm}$. from the open end of the tube. The tube is cut off at the desired length and the other end sealed to prevent the entrance of liquid. When cold, the tube is placed open end down in the liquid to be boiled. The open end should rest on the bottom of the vessel containing the liquid and should remain there during use. When liquids of high specific gravity are being boiled, it is necessary, therefore, to have the capillary so heavy that it will not be thrown off the bottom. This weight can be obtained by drawing out the tube from which the capillary is made only near the seal, or by using a very thick walled tube.

In a general way the theory of the action of such a tube is that

1 Compt. Rend., 86, 472 
when heated the air in the capillary expands and passes through the liquid in bubbles. The vapor of the liquid gradually replaces the air and the stream of bubbles is continuous as long as the temperature around the capillary is at the boiling-point of the liquid. This constant bubbling prevents superheating and consequent explosive boiling. It is apparent that the size of the bubble will depend chiefly on the width of the capillary. This should vary with the nature of the liquic. For liquicls of low boilingpoint or for frothing liquids a narrow capillary is best, while for heavy liquids a wider capillary (even as wide as $5 \mathrm{~mm}$. internal diameter) is more suitable.

When boiling with a return condenser, the seal of the capillary must be below the surface of the liquid. If the seal is above the surface, cold drops falling back from the condenser will strike the capillary and cause condensation of the vapor inside it, thus stopping the stream of bubbles. To prevent displacement, the capillary should be of such a length that the upper end reaches nearly to the top of the neck of the flask. When the liquid is in a thin broad layer the capillary should be bent at the seal so as to be parallel or nearly parallel to the bottom of the flask. In boiling liquids in a test-tube, care must be taken that the heat is applied at the bottom of the tube. When a solid is being dissolved, or when in the course of a reaction a solid is being precipitated out of solution, the capillary should be examined from time to time to see that the end has not become clogged.

The capillary is useless, if completely filled. Therefore it must be cold and empty when placed in the liquid. Care should be taken (especially in the case of liquids that usually bump badly) to protect the flame from drafts, so that the temperature of the liquid shall not temporarily fall below the boiling-point, allowing the capillary to fill.

Other minor changes and precautions may be advisable at times, but it will be found that they depend on the following principles. The capillary must never be allowed to become filled with liquicl. The greater the amount of air there is to drive out (depending on the width of the capillary and the distance from the seal to the open end), the longer will it take to get a rapid stream of bubbles of vapor of the liquid. The greater the distance from the seal to the open end, the longer will it take to fill the capillary on cooling. 
This method has been in successful use in these laboratories for nearly a year. By its use it is possible to saponify esters by boiling with a 50 per cent. solution of potassium hydroxide (using a return condenser) or to boil concentrated sulphuric acid in a testtube, without any bumping. Only two cases have been met with in which bumping persisted after the capillary was introduced. Both were reactions carried out with a return condenser. Although the bumping continued, it was so greatly lessened that the liquid was not thrown out of the upper end of the condenser and there was no danger of having the flask broken.

Massachusetts Institute of Techxology,

November, 1902 .

[CONTRIBUTIONS FROM THE LABORATORIES OF THE MASSAChUSETTS INSTITUTE OF TECHNOLOGY.]

\title{
THE EQUIVALENT CONDUCTIVITY OF THE HYDROGEN ION DERIVED FROM TRANSFERENCE EXPERI- MENTS WITH HYDROCHLORIC ACID.
}

\author{
BY A. A. NoYes.
}

Received November 19, I902.

(SECOND PAPER.)

IN a previous communication ${ }^{1}$ bearing the same title made by A. A. Noyes and G. V. Sammet three series of determinations of the transference-numbers for $1 / 60$ molar hydrochloric acid, at $10^{\circ}$, $20^{\circ}$, and $30^{\circ}$, respectively, were presented, from which by combination with the fairly accurately known values for the conductivity of the chlorine ion, the following ones for that of the hydrogen ion were obtained.

$\begin{array}{cccccc}t . & 10^{\circ} . & 18^{\circ} . & 20^{\circ} . & 25^{\prime} . & 30^{\circ} . \\ \Lambda & 288.7 & 329.8 & 340.0 & 364.9 & 389.1\end{array}$

These values are 4 to 6 per cent. higher than those derived by Ostwald and Kohlrausch through a consideration of the change of conductivity of strong acids with the dilution. It was not considered possible that this divergence could arise from experimental errors in the transference determinations; but it was suggested that it might be due, at any rate in part, to a difference in the transference-numbers of the acid at extreme dilution and at the investigated dilution of 60 liters. To test this possibility, a new series of determinations has been made at $20^{\circ}$ with an approxi-

1 This Journal, 24, 944 (1902). 